\title{
O ALCANCE TEÓRICO DAS CATEGORIAS “EXCLUSÃO E LIBERTAÇÃO” PARA A QUESTÃO AMBIENTAL: UMA LEITURA ANCORADA EM DUSSEL E FREIRE'
}

\author{
THE THEORETICAL SCOPE OF THE CATEGORIES “EXCLUSION AND LIBERATION” FOR THE \\ ENVIRONMENTAL ISSUE: A READING ANCHORED IN DUSSEL AND FREIRE
}

EL ALCANCE TEÓRICO DE LAS CATEGORIAS EXCLUSIÓN Y LIBERACIÓN PARA LA CUESTION AMBIENTAL: UNA LECTURA ANCLADA EN DUSSEL Y FREIRE

\author{
César Augusto Soares da Costa ${ }^{1}$ \\ Carlos Frederico Bernardo Loureiro ${ }^{2}$
}

\begin{abstract}
RESUMO
Este estudo recupera os conceitos de exclusão e libertação que são fundamentais para o entendimento das obras de Enrique Dussel e Paulo Freire, em suas interfaces e complementaridades, visando a contribuir com formulações teóricas oriundas do pensamento latino americano para a questão ambiental. $O$ interesse na reflexão destes dois pensadores à luz do debate sobre a exclusão e libertação se justificava por serem indiscutíveis referências do campo crítico com larga influência não somente na educação, mas também nos movimentos sociais, na Teologia e Filosofia da Libertação e no pensamento filosófico e sociológico da América Latina. Assim, o presente trabalho está sistematizado em três tópicos, que se seguem à introdução, onde reiteramos a importância do pensador argentino Enrique Dussel e do educador brasileiro Paulo Freire enquanto intelectuais que tematizaram pedagógica e filosoficamente de forma crítica a América Latina ( $A L)$. Inicialmente, versaremos sobre a relevância do debate sobre a exclusão no debate ambiental e suas implicações filosóficas, pedagógicas, sociais e políticas na relação sociedade-natureza no projeto societário capitalista. Em seguida, abordaremos o conceito político do termo libertação para estes autores em suas aproximações diante a questão ambiental na realidade latino-americana. Nas conclusões, indicaremos de forma geral alguns elementos político-pedagógicos do pensamento de Dussel e Freire para a discussão ambiental crítica à luz da exclusão e da libertação, de forma a questionarmos a subjugação da natureza e a condição daqueles que historicamente estão postos como subalternos pelo projeto capitalista à luz do projeto de transformação social proposta pelos pensadores.
\end{abstract}

PALAVRAS-CHAVE: Enrique Dussel. Exclusão. Libertação. Paulo Freire. Questão ambiental.

\footnotetext{
${ }^{1}$ Doutor em Educação Ambiental - Universidade Federal do Rio Grande (FURG), Rio Grande, RS - Brasil. Professor Assistente da Universidade Católica de Pelotas (UCPel), Pelotas, RS - Brasil. E-mail: csc193@hotmail.com

${ }^{2}$ Doutor em Serviço Social - Universidade Federal do Rio de Janeiro, UFRJ, Rio de Janeiro, RJ - Brasil. Professor Associado da Universidade Federal do Rio de Janeiro, UFRJ, Rio de Janeiro, RJ - Brasil. E-mail: fredericoloureiro89@gmail.com
}

Submetido em: 22/10/2015 - Aceito para publicação em: 30/05/2016

(C) ETD-Educação Temática Digital Campinas, SP $\quad$ v.19 $\quad$ n.1 $\quad$ p. 234-257 jan./mar. 2017 


\section{ABSTRACT}

This study recovers the concepts of exclusion and liberation that are fundamental to the understanding of the works of Enrique Dussel and Paulo Freire in their interfaces and complementarities, in order to contribute to theoretical formulations derived from the Latin American thought to the environmental issue. Interest in reflection of these two thinkers in the light of the debate on exclusion and release was justified because they are unquestionable references the critical field with wide influence not only in education but also in the social movements in theology and philosophy of liberation and philosophical thought and sociological Latin America. Thus, this work is systematized in three topics, following the introduction, which reiterate the importance of the Argentine thinker Enrique Dussel and the Brazilian educator Paulo Freire while intellectuals who tematizaram pedagogical and philosophical critically Latin America (LA). Initially, versaremos about the relevance of the debate on exclusion in the environmental debate and its philosophical implications, educational, social and political in the relationship between society and nature in the capitalist social project. Then we discuss the political concept of the term release for these authors in their approaches on environmental issues in the Latin American reality. The findings in general indicate some political and pedagogical elements of thought Dussel and Freire for environmental critical discussion in the light of exclusion and release in order to question the subjugation of nature and the condition of those who are historically placed as a junior at capitalist project in the light of the project of social transformation proposed by thinkers.

KEYWORDS: Enrique Dussel Exclusion. Libertation. Paulo Freire. Environmental Issues.

\section{RESUMEN}

Este estudio se recupera los conceptos de exclusión y de liberación que son fundamentales para la comprensión de la obra de Enrique Dussel y Paulo Freire en sus interfaces y complementariedades, a fin de contribuir a las formulaciones teóricas derivadas del pensamiento latinoamericano en el tema ambiental. El interés por la reflexión de estos dos pensadores de la luz del debate sobre la exclusión y la liberación estaba justificada porque son referencias indiscutibles del campo crítico con gran influencia no sólo en la educación, sino también en los movimientos sociales en la teología y la filosofía de la liberación y el pensamiento filosófico y sociológica América Latina. Por lo tanto, este trabajo se sistematiza en tres temas, a raíz de la introducción, que reiteran la importancia del pensador argentino Enrique Dussel y el educador brasileño Paulo Freire, mientras que los intelectuales que tematizaram pedagógica y crítica filosófica América Latina ( $A L)$. Inicialmente, versaremos sobre la relevancia del debate sobre la exclusión en el debate ambiental y sus implicaciones filosóficas, educativas, sociales y políticos en la relación entre la sociedad y la naturaleza en el proyecto social capitalista. A continuación se discute el concepto político de la liberación plazo para estos autores en sus enfoques sobre temas ambientales en la realidad latinoamericana. Los resultados, en general, indican algunos elementos políticos y pedagógicos de pensamiento Dussel y Freire para la discusión crítica del medio ambiente a la luz de la exclusión y la liberación con el fin de cuestionar el sometimiento de la naturaleza y la condición de los que se sitúan históricamente como un junior en proyecto capitalista, a la luz del proyecto de transformación social propuesto por pensadores.

PALABRAS CLAVE: Enrique Dussel. Exclusión. Liberación. Paulo Freire. Cuestion ambiental. 


\section{EDUCAÇÃO E EXCLUSÃO NA AMÉRICA LATINA: O OLHAR DUSSELIANO E FREIREANO}

A reflexão que nos propusemos neste ensaio, visa tratar de contribuições teóricas sobre os conceitos de "exclusão e libertação" a partir da relação pedagógica estabelecida entre Enrique Dussel e Paulo Freire, apontando convergências à luz da questão ambiental crítica. Cabe recordar que para esta perspectiva epistêmica-política, os problemas ambientais são determinados socialmente e situados historicamente, não sendo possível superá-los sem o enfrentamento e transformação do conjunto de relações humanas e sociais que nos constituem como seres sociais naturais (LOUREIRO, 2012; 2009; LUKÁCS, 1979).

O filósofo argentino e o pedagogo brasileiro são duas grandes referências do pensamento revolucionário, filosófico e pedagógico latino-americano, a partir dos quais temos a intenção de identificar algumas categorias teóricas que nos auxiliam a refletir as práticas educativas ambientais diante a dinâmica do capital. Acreditamos que esse movimento de aproximação teórica é relevante, uma vez que temos uma grande quantidade de pesquisas no campo ambiental em vários programas de pós-graduação que não abdicam do trabalho de procurar os elos que unem os povos a partir de uma história comum e do movimento de superação das relações sociais alienadas no capitalismo como condição para a materialização de novas relações sociais com/na natureza.

É à luz dos nossos autores que compreendemos que a libertação filosófica e a libertação política se completam e são inseparáveis, pois contemplam todas as dimensões da vida pessoal e coletiva. Assim, possibilitam-nos instrumentos teórico-práxicos para libertação integral, não só como sujeitos, mas enquanto sociedade, impelindo-nos a uma nova ordem social justa e igualitária. A necessária aproximação entre exclusão latinoamericana e reconhecimento da dimensão ambiental como ponto de partida para uma redefinição do atual projeto societário, requer em ancorar neste método de abordagem na realidade visando transformá-la radicalmente. Tal abordagem envolve compreensões da questão ambiental como fruto de sistema-mundo moderno colonial (DUSSEL, 2000) e seu ideário dominante porque alijou o povo latino-americano de sua condição e realização (ASSMANN E SUNG, 2000).

No entendimento de Dussel:
(C) ETD- Educação Temática Digital
Campinas, SP
v.19 n.1
p. $234-257$ jan./mar. 2017 
Até muito recentemente a política não tinha descoberto sua responsabilidade ecológica [...] A previsão de permanência da vida da população de cada nação na humanidade que habita o planeta Terra é primeira e essencial função da política [...] Uma humanidade extinta obviamente aniquilaria o campo político e todos seus sistemas possíveis (2007, p. 64).

O marco inicial para refletir a exclusão e suas implicações na questão ambiental é de que nossas sociedades estão em dívida com enormes parcelas da população condenadas a viverem em estados de "sub-emancipação". No mesmo sentido, várias práticas educativas ambientais supostamente voltadas para emancipação não estão inseridas numa trajetória de lutas sociais, que foram ignoradas, silenciadas ou esquecidas em nossa caminhada pedagógica. Constata-se que parte dos pesquisadores não se preocupa com a tarefa social da ciência num país de tantas exclusões, isto é, não dialetizam porque as políticas públicas obedecem mais a ética do mercado do que objetivam um compromisso efetivo com o direito das pessoas, de modo a dar condições à dignidade humana (ANDREOLA, 2003). Indicamos em nosso ensaio, que este desafio:

\begin{abstract}
Trata-se de buscar condições para a superação da colonialidade pedagógica impregnada na América Latina e sua história colonial de mais de quatro séculos. Com a chegada dos europeus foram subordinados as histórias e as cosmologias dos povos que aqui habitavam. A colonialidade pedagógica sinaliza o sentimento de inferioridade, com todas as ausências que se produzem nos relatos da modernidade como resultado de uma construção europeia de história, aqui realizada, a favor dos interesses de Europa (STRECK; ADAMS; MORETTI, 2010, p. 22).
\end{abstract}

A lógica latino-americana, se expressa pela distribuição desigual da riqueza, uso intensivo de recursos naturais e pelo domínio da epistemologia, radicalizados desde o estabelecimento do sistema de classificação hierárquica em todas as esferas sociais até a supressão de economias e culturas existentes antes da chegada dos colonizadores (DUSSEL, 2000). Negar as origens das civilizações estabelecidas antes da colonização atravessa a história da América Latina. Os colonizados, por sua vez, como forma de resistência, aprenderam a cultura dos dominadores, tanto no campo da atividade material quanto da prática religiosa que engendrava uma subjetividade colonizada. Dentro desta perspectiva, colonialidade e independências colocam-se de forma contraditória e dinâmica na luta dos povos indígenas e afrodescendentes pela emancipação política (STRECK, ADAMS, MORETTI, 2010).

Levando em conta os aspectos acima, compartilhamos da necessidade de uma aproximação teórica de Enrique Dussel e Paulo Freire frente à questão da exclusão e da libertação em suas implicações para o debate ambiental, uma vez que a colonialidade sob o

(C) ETD- Educação Temática Digital Campinas, SP $\quad$ v.19 $\quad$ n.1 $\quad$ p. 234-257 jan./mar. 2017 
modo de produção capitalista impede, em termos freireanos, o ser humano de ser-mais (COSTA, 2011; COSTA E LOUREIRO, 2013). Sendo assim, temos clareza teórica que Freire não se dedicou especificamente ao estudo da educação ambiental, mas suas amplas reflexões abrem possibilidades para refletirmos as relações sociedade-natureza a partir de sua teoria do conhecimento e do seu método pedagógico. De forma ampla, Paulo Freire pressupõe sua concepção educativa compromissada com a luta pela transformação social, colocando a partir de posição ética, crítica, radical e revolucionária.

Sob um "olhar ambiental" postulamos que a profundidade do pensamento freireano, incide pela insistência de reinventá-lo no contexto de cada luta específica. Assim, o que precisa ser conservado em cada momento é a sua constante insistência numa ética da solidariedade, que implica ser a sua utopia e incansável esperança nas possibilidades históricas de humanização do mundo (STRECK, REDIN, ZITKOSKI, 2010). Logo, esse horizonte de reinventar e trazer Freire em diálogo com a questão ambiental também nos indica que:

\begin{abstract}
É preciso, também, reinventar Paulo Freire na era da globalização do capital, dos novos arranjos econômicos do mundo do mercado e das políticas educacionais neoliberais, das novas tecnologias de comunicação e informação que manipulam a opinião pública, geralmente sob o interesse do poder econômico. Tudo isso exige reinventar, também, novas formas de luta revolucionárias, tendo presentes as novas condições sociais e materiais nas quais os sonhos individuais e coletivos são gerados, alimentados, ou diminuídos e frustrados (STRECK; REDIN; ZITKOSKI, 2010. p. 22).
\end{abstract}

Estes elementos acima ficam explícitos na posição que o pensamento freiriano assume para este ensaio (LAYRARGUES, 2014, p. 12), pois:

Para que o pensamento freiriano possa contribuir de fato na construção de outro mundo, que seja socialmente justo, ecologicamente prudente, politicamente atuante, culturalmente diverso, economicamente suficiente, ele não pode ser compreendido de forma superficial, desatenta, ingênua, descompromissada.

Já o filósofo argentino constata a preocupação fundamental com a libertação dos sujeitos envolvido no processo de opressão do sistema colonial europeu, cujo processo deixou chagas sociais em nosso continente. Desse modo, Dussel nos propõe refletir sobre a nossa condição de sujeitos inseridos na realidade social, para que possamos desenvolver uma perspectiva crítica dos acontecimentos sociais, políticos, culturais e econômicos sociais, políticos, culturais e econômicos em torno do sistema-mundo moderno colonial vigente. A sua Filosofia da Libertação se apresenta num propósito único: libertar filosóficopoliticamente (DUSSEL, 1986). Ou seja, quer libertar-nos politicamente, mostrando-nos alguns mecanismos de dominação e exploração que normalmente nos passam despercebidos ao cotidiano.

(C) ETD- Educação Temática Digital Campinas, SP v.19 $\quad$ n.1 $\quad$ p. 234-257 jan./mar. 2017 
A partir disso, analisa criticamente o discurso eurocêntrico moderno e a possibilidade de superação do irracionalismo moderno por meio da razão críticolibertadora. Dussel está para além de uma mera reflexão racional de constatação da negação do sujeito humano uma vez que sua teoria se constitui em uma ética crítica, ou seja, "da transformação como possibilidade da reprodução da vida da vítima e como desenvolvimento factível da vida humana em geral" (DUSSEL, 2000, p. 564).

Tendo estas premissas iniciais, que o presente trabalho está sistematizado em três tópicos, que se seguem à introdução, onde reiteramos a importância do pensador argentino Enrique Dussel e do educador brasileiro Paulo Freire enquanto intelectuais que tematizaram pedagógica e filosoficamente de forma crítica a América Latina (AL). Primeiramente, versaremos sobre a relevância do debate sobre a exclusão no debate ambiental e suas implicações filosóficas, pedagógicas, sociais e políticas na relação sociedade-natureza no projeto societário capitalista. Em seguida, abordaremos o conceito político do termo libertação para estes autores em suas aproximações diante a questão ambiental na realidade latino-americana. Por fim, nas considerações finais, indicaremos de forma geral alguns elementos políticos do pensamento de Dussel e Freire para a discussão ambiental crítica à luz da exclusão e da libertação, de forma a questionarmos a subjugação da natureza e a condição daqueles que historicamente estão postos como subalternos pelo projeto capitalista à luz do projeto de transformação social proposta pelos pensadores.

\section{CONCEITUANDO A EXCLUSÃO NO DEBATE AMBIENTAL}

Temos presente que o debate do conceito de exclusão na discussão ambiental é fundamental para a compreensão do mundo, pois a destruição ambiental segundo o marco da modernidade pode ser visto por dois aspectos (DUSSEL, 2000, p. 65-66): a) constituiu a natureza como um "objeto explorável" com vistas ao lucro capitalista em termos econômicos; e, b) a destruição da própria humanidade através do capitalismo.

O desenvolvimento do capitalismo expõe desde o seu princípio, que o processo de acumulação impôs a necessidade de expandir fronteiras a todas as regiões do mundo para a exploração de seus recursos, assim como a força de trabalho. Tal processo começa a configurar-se na fase de desenvolvimento mercantil. Nesse período, o capital conseguiu mercantilizar os minerais, os vegetais, os animais e o espaço natural que havia permanecido usufruto das sociedades pré-capitalistas.

\section{(C) ETD-Educação Temática Digital Campinas, SP v.19 $\quad$ n.1 $\quad$ p. 234-257 jan./mar. 2017}


Esse processo de saqueamento dos recursos naturais tornou-se uma guerra de extermínios: animais mortos em numerosas zonas do planeta; ouro e prata pilhados da América, convertidos em moeda; destruição das florestas com a introdução da agricultura; e retirada de madeiras para a transformação em carvão. Pode-se dizer que essa pilhagem de recursos naturais é uma tendência exclusiva de comportamento em relação ao meio ambiente própria do modelo de produção capitalista (PINTO; ZACARIAS, 2010, p. 45).

Segundo Foster (2005), através da "falha metabólica" a exploração da natureza no processo de acumulação do capital torna-se condição indispensável. Assim, "o conceito de "falha metabólica" permite evidenciar como a agricultura e a indústria de larga escala se conjugam para explorar tanto o trabalhador quanto a natureza, perturbando, assim, o metabolismo social" (ZACARIAS, 2012, p. 50). Estes fatores são mencionados por Marx (1996, p. 121-122) em O Capital:

\begin{abstract}
Com a preponderância sempre crescente da população urbana que amontoa em grandes centros, a produção capitalista acumula, por um lado, a força motriz histórica da sociedade, mas perturba, por outro lado, o metabolismo entre homem e terra, isto é, o retorno dos componentes da terra consumidos pelo homem, sob forma de alimentos e vestuário, à terra, portanto, a eterna condição natural de fertilidade permanente do solo. Com isso, ela destrói simultaneamente a saúde física dos trabalhadores urbanos e a vida espiritual dos trabalhadores rurais. Mas, ao destruir as condições desse metabolismo, desenvolvidas espontaneamente, obriga-o, simultaneamente, a restaurá-lo de maneira sistemática, como lei reguladora da produção social e numa forma adequada ao pleno desenvolvimento humano. [...] Assim como na indústria citadina, na agricultura moderna o aumento da força produtiva e a maior mobilização do trabalho são conseguidos mediante a devastação e o empestamento [comprometimento] da própria força de trabalho. $\mathrm{E}$ cada progresso da agricultura capitalista não é só um progresso na arte de saquear o trabalhador, mas ao mesmo tempo na arte de saquear o solo, pois cada progresso no aumento da fertilidade por certo período é simultaneamente um progresso na ruína das fontes permanentes dessa fertilidade. [...] Por isso, a produção capitalista só desenvolve a técnica e a combinação do processo de produção social ao minar simultaneamente as fontes de toda riqueza: a terra e o trabalhador.
\end{abstract}

No âmbito industrial, a natureza é impactada de forma dupla, tanto pela exploração das matérias primas, quanto pela poluição dos resíduos de sua produção que retornam à natureza em forma de poluentes. "Pode-se dizer que o conceito de falha metabólica permitiu a Marx demonstrar que a degradação ambiental tem causas econômicas e políticas, ligadas a um processo de dupla exploração: do trabalho e da natureza. Além disso, permite demonstrar que as condições de sustentabilidade impostas pela natureza têm sido violadas" (ZACARIAS, 2012, p. 50-51). Dessa forma, apontamos que a
(C) ETD- Educação Temática Digital
Campinas, SP
v.19 n.1
p. $234-257$
jan./mar. 2017 
primeira tendência do capitalismo é a produção ilimitada, fruto direto e fundamental de um modelo econômico que gira em torno da produção de lucro e não em satisfazer as necessidades (FOLADORI, 2001).

Segundo Mészáros (2007), a criação de uma relação mais ecológica não é um problema isolado, mas uma parte essencial, até mesmo definidora da luta para criar uma nova ordem social visando à realização das necessidades humanas.

Assim, a ecologia [...] é um aspecto importante, mas subordinado, da necessária redefinição qualitativa do uso de bens e serviços produzidos, sem o qual a defesa da ecologia permanentemente sustentável da humanidade - novamente, uma necessidade absoluta - pode ser nada mais que uma piedosa esperança (MÉZSÁROS, 2007, p. 260-61).

Dessa forma, é essencial que o caminho para tal solução passe pelo rompimento radical com o projeto societário vigente, incluindo um processo revolucionário que conduza ao trabalho associado e à emancipação humana. Essa é a determinação maior a ser enfrentada uma vez que a contradição do capital está em não conseguir separar o "avanço" da destruição, nem o "progresso" de desperdício (MÉSZÁROS, 2009). De outra forma:

É inabalável a determinação do capital em devorar as condições materiais de existência humana e transformá-las em objeto de lucro. Quanto à destruição das condições de vida na terra, se houver quem pague por seu aniquilamento, o capital não terá receio em destruí-la e isso não será nenhum problema, afinal, o capital não se nutre de humanidade, sim de mais-valia. É dessa forma que qualquer tentativa de reverter a tendência destrutiva do sistema metabólico do capital em tempos de crise estrutural esbarra nos requisitos de manutenção orgânica do próprio sistema. Eis um significativo traço indelével da incontrolabilidade do capital e de sua incapacidade de considerar os seres humanos com tais (BARROS, 2013, p. 29).

Streck (2009, p. 547) compreende a atualidade da discussão sobre a exclusão desse modo:

\begin{abstract}
Caracterizada como opressão nas décadas de 1960 e 1970, a exclusão social não se refere a algo novo nem uniforme, posto que a generalização do uso da expressão exclusão no campo da educação se deve a um conjunto de fatores, alguns deles atravessando os campos ideológicos, o que faz com que a expressão tenha um apelo de universalidade. As décadas de 1980 e 1990 correspondem a um movimento multifacetado da sociedade, com muitas contradições em todos os sentidos. Se, por um lado, houve o avanço das políticas neoliberais, é também o período da promulgação, na nova Constituição brasileira, da consolidação da institucionalidade democrática e da eleição de governos populares.
\end{abstract}

Sobre o uso corrente que o termo possui, Oliveira (2004b, p. 60) sinaliza que:

(C) ETD-Educação Temática Digital Campinas, SP v.19 $\quad$ n.1 $\quad$ p. 234-257 jan./mar. 2017 
a partir do último quarto do século XX, o termo exclusão começou, gradualmente, a ocupar espaços na literatura social, especialmente a partir da área das políticas públicas. Hoje, está fortemente presente em todas as áreas. Na maioria das ciências sociais, é empregado como se fosse um conceito científico de uso corrente, que já não mais precisasse ser definido; no campo das políticas públicas e da assistência social, constitui-se, inconfundivelmente, em alvo prioritário das ações; até mesmo certos movimentos religiosos, cujo conceito de "pobre" transcende o significado sociológico, renderam-se ao magnetismo do "excluído". Quem são, entretanto, os excluídos? Ora o termo refere-se às minorias étnicas, ora aos segregados pela cor; por vezes aos desempregados de longa duração, outras vezes aos sem-moradia; em certos casos, aos que fazem opções existenciais contrárias à moral vigente, em outros aos portadores de deficiências, aos aidéticos, aos velhos ou mesmo aos jovens. Excluídos, entre nós, são os desempregados, os subempregados, os trabalhadores do mercado informal, os sem-terra, os moradores de rua, os favelados, os que não têm acesso a saúde, educação, previdência etc., os negros, os índios, as mulheres, os jovens, os velhos, os homossexuais, os alternativos, os portadores de necessidades especiais, enfim, uma relação quase interminável (2004, p. 160).

Os argumentos acima expõem as raízes do tema da exclusão e que encontra no debate ambiental crítico pertinência. Da mesma forma, tal discussão alcançou validade no âmbito do debate sociológico, filosófico e pedagógico como veremos.

Paulo Freire, por sua vez, em sua Pedagogia do Oprimido, indicava uma obra voltada "(a) os esfarrapados do mundo e aos que neles se descobrem e, assim, descobrindose, com eles sofrem, mas, sobretudo, com eles lutam" (1983, p. 17). Em sua Pedagogia da autonomia, ele reafirma o ponto de vista como sendo o dos "condenados da Terra, o dos excluídos" (1996, p. 16). O autor incorpora este novo conceito com uma naturalidade surpreendente. Pode-se argumentar que assumir esta nova nomenclatura faz parte do posicionamento epistemológico efetivado no livro Pedagogia da esperança (1992), quando a metáfora da trama assume uma importância central, sinalizando a necessidade de ser pósmodernamente progressista (STRECK, 2004).

Um ano antes da publicação de Pedagogia da autonomia havia sido lançada a coletânea Pedagogia da exclusão: crítica ao neoliberalismo em educação (GENTILI, 1996). O livro trouxe temas como a privatização do ensino, o Banco Mundial, as políticas da educação, os mercados educacionais e o avanço da nova direita. Nas "Notas preliminares" Gentili (1996, p.9), aponta para o fato de que estes trabalhos "permitem caracterizar a ofensiva neoliberal como uma nova pedagogia da exclusão."

Dentro deste panorama, a concepção de exclusão aparece vinculada ao neoliberalismo, contra o qual se volta por não permitir espaço para a ação dos homens enquanto/como sujeitos da sua própria história. Para Ferraro (2000) o neoliberalismo é um

(C) ETD-Educação Temática Digital Campinas, SP v.19 $\quad$ n.1 $\quad$ p. 234-257 jan./mar. 2017 
movimento que objetiva resgatar o ideário do liberalismo em decorrência da longa crise pela qual passou o capitalismo entre 1880 e 1940 . Neste período, o liberalismo perdeu força para o desenvolvimento das economias planificadas dos regimes socialistas, do keynesianismo ou do Estado de Bem-Estar Social. Desta forma, Ferraro (2000, p. 25-26) postula que o neoliberalismo tem em seu marco:

[...] divinização do Mercado e satanização do Estado. Estado passou a significar opressão, atraso, megalomania, incompetência e corrupção. Em contrapartida, o Mercado passou a ser cantado como o jardim onde florescem a liberdade, a modernidade, o progresso, a competência, a honestidade, a qualidade, e até a qualidade total. Pode-se dizer que a fé e o programa neoliberais se resumem nos seguintes dois artigos, por sinal, complementares: Estado Mínimo e Livre Mercado.

Para Ribeiro (1999, p. 42) "a realidade da exclusão que a faz visível não pode ser dissociada dos processos de destruição de uma política de direitos de cidadania, saúde, educação, segurança, habitação, regulamentação do trabalho - instituídos com o Estado social". Esta perda de lugares sociais, garantidos por empregos, por direitos e por reconhecimento (que os cientistas sociais tecem suas críticas), define os excluídos como objetos de assistência e políticas de inserção. Sendo que esta discussão indica que "a exclusão está amarrada ao desemprego estrutural e tecnológico, em que uma política de lucratividade delibera sobre a transformação de trabalhadores em lixo industrial e à destruição de toda uma legislação de amparo ao trabalhador, o qual, tornado lixo, se presume que dela não necessite" (RIBEIRO, 1999. p. 43). No entendimento de Ferraro (2000, p. 31):

A onda neoliberal não é, portanto, nem variante, nem produto final de um desenvolvimento continuado do ideário liberal; muito pelo contrário, o neoliberalismo é o resultado de um longo período de crise do mundo capitalista e do desgaste desse ideário. Representa, por um lado, uma reação contra as novas concepções e propostas que abriram caminho para o planejamento econômico, o keynesianismo e as políticas de bem-estar social, e, por outro, a afirmação explícita de retorno às idéias e ideais que nortearam a grande expansão industrial no século XIX (FERRARO, 2000, p. 31).

Assmann (1996, 2000) emprega o conceito exclusão para referir-se à lógica excludente do mercado capitalista. Mas ainda cabe a seguinte pergunta: excluídos de que? Neste sentido, é importante ressaltar que do ponto de vista ontológico permanecem as relações de interdependência com o restante da humanidade e com os demais seres da natureza. Além disso, tais pessoas categorizadas como "excluídas" não estão à margem dos meios de comunicação de massa que socializa o pensamento dominante e a ideologia do consumo. Assmann (1996) entende que a exclusão tenha se tornado uma espécie de palavra-síntese para referir-se às novas características das desigualdades sociais no mundo.

(C) ETD-Educação Temática Digital Campinas, SP v.19 $\quad$ n.1 $\quad$ p. 234-257 jan./mar. 2017 
"Dívida social, apartheid social, e expressões similares, não expressam da mesma maneira o círculo vicioso da exclusão" (p. 214). Assinala algumas características deste fenômeno da exclusão, entre as quais se destaca a existência de um enorme contingente de "inaproveitáveis" ou "desnecessários", a "massa sobrante". Posição próxima a que é sustentada por Martins (1997).

O uso do binômio exclusão social/inclusão social encontra sua pertinência no contexto da denúncia e do pragmatismo, no qual paradoxalmente também se revelam os seus limites. A potencialidade como fator de denúncia fica evidente na grande marcha que a cada ano é realizada sob setores progressistas da Igreja Católica com o nome de Grito dos Excluídos e também na mescla de grupos que compõem o Fórum Social Mundial (STRECK, 2004). Sob este cenário, podemos evidenciar que:

Existe uma correspondência entre exclusão social e os assim chamados novos movimentos sociais, que têm no reconhecimento identitário uma importante bandeira de luta. Podem ser as mulheres, os jovens, os negros, os índios, os semterra ou os sem-teto, cada um deles por sua vez eventualmente subdividido em novos grupos. Na ecologia, pode haver grupos que lutam pela sobrevivência de uma espécie vegetal ou animal, grupos que lutam pela preservação da Amazônia, contra a ocupação predatória do solo etc. Todos eles encontram sob o manto da exclusão social algum tipo de abrigo. Talvez se pudesse dizer que o deslizamento linguístico da opressão/libertação para exclusão/inclusão social implica um deslocamento do político para o ético. Libertação era um conceito de mobilização política da classe oprimida em busca da construção de outra sociedade. Na medida em que os contornos do horizonte dessa libertação se tornaram mais difusos, o conceito perde muito de sua força. Isso se deve tanto a fatores internos, com a assunção do poder por forças progressistas que frustram expectativas, como a fatores externos simbolizados na queda do muro de Berlim e à consequente sensação da impossibilidade de construção de alternativas que tenham condições de se sustentar no cenário global (STRECK, 2009, p. 552).

Dentro da perspectiva de que a exclusão é inerente ao capitalismo, Oliveira (2004a, p. 146) conclui sua tese a partir de Karl Marx afirmando que esta não pode constituir-se num conceito capaz de representar um novo paradigma social. Reflexão que é revista por Ghiggi e Oliveira (2007, p. 28) que apontam que não estaríamos diante "de qualquer novidade substantiva que requeira um novo paradigma. (...) O modelo exclusão/inclusão é típico de uma perspectiva positivista-funcionalista, que apenas visa a corrigir as disfunções sociais, reatar os laços rompidos, supondo intocável a estrutura social".

Martins (2002) parte do mesmo pressuposto de que não se está diante de um novo dualismo, ressaltando em seus estudos que a sociedade que exclui é a mesma que inclui, no sentido de gerar formas desumanas de integração e participação no mesmo corpo social.

(C) ETD-Educação Temática Digital Campinas, SP v.19 $\quad$ n.1 $\quad$ p. 234-257 jan./mar. 2017 
Para o autor, "a novidade da chamada exclusão social é a sua velhice renovada" (p. 14). No entanto, segundo ele, a definição de exclusão social para identificar as desigualdades sociais hoje estaria também revelando um dos novos aspectos da sociedade de classes, ou seja, que a classe operária não mais ocupa o centro das explicações das lutas sociais. Para esta compreensão, Martins (1997) recorre historicamente apontando que o problema da exclusão surge com a sociedade capitalista, pois sua lógica é o mercado, é o movimento, é a livre circulação no qual que tudo tem que ser sinônimo de riqueza que circula, ou seja, de mercadoria.

Neste foco, Martins conclui que:

O capitalismo na verdade desenraiza e brutaliza a todos, exclui a todos. $\mathrm{Na}$ sociedade capitalista essa é uma regra estruturante: todos nós, em vários momentos de nossa vida, e de diferentes modos, doloroso ou não, fomos desenraizados e excluídos. É próprio dessa lógica de exclusão a inclusão. A sociedade capitalista desenraiza, exclui para incluir, incluir de outro modo, segundo suas próprias regras, segundo sua própria lógica. O problema está justamente nessa inclusão (MARTINS, 1997, p. 32).

Igualmente, dois pontos importantes de Freire podem ser incorporados ao debate sobre a exclusão social. Se existem marginalizados, não é por opção dos mesmos. Desse modo, os marginalizados seriam vítimas de uma violência que os expulsa do sistema. $\mathrm{Na}$ realidade, são violentados, mas estão sempre "dentro da realidade social" (FREIRE, 1979, p. 47). Constata-se que Freire jamais abre mão de recolocar o problema nos marcos da sociedade de classe! "É neste contexto, chamando a atenção para a violência e para a desumanização próprias da sociedade de classe, que Freire refere-se ao homem marginalizado como "excluído do sistema social" (FREIRE, 2001, p. 74) (OLIVEIRA, 2010, p. 168).

\title{
3 SITUANDO A EXCLUSÃO E LIBERTAÇÃO NA PERSPECTIVA POLÍTICA DE DUSSEL E FREIRE
}

Convém neste momento da discussão sobre exclusão, apontar o que Paulo Freire e Enrique Dussel entendem pelo termo "libertação", mas antes de tudo, explicitando seus principais postulados. No caso de Freire, a relação opressor-oprimido, no caso de Dussel, a antinomia alienação- libertação frente ao campo ambiental.

Freire, ao lidar com o problema conceitual da exclusão nos ajuda a compreender a temática em sua dinâmica histórica:

\author{
(C) ETD-Educação Temática Digital Campinas, SP v.19 $\quad$ n.1 $\quad$ p. 234-257 jan./mar. 2017
}


Em Educação como prática da liberdade, a ideia de trânsito - do homem-objeto ao homem-sujeito, da sociedade fechada à sociedade aberta, da consciência ingênua à consciência crítica - expressa a expectativa de uma mudança em vias de realização por meio dos projetos que, naquela época de grande mobilização popular, estavam sendo desenvolvidos. Na Pedagogia do oprimido torna-se central a noção de conflito entre oprimidos e opressores, numa ruptura com a linearidade sugerida pelo conceito de trânsito. Em Pedagogia da esperança, a metáfora da trama indica novos tempos, novas leituras e novas pedagogias. A continuidade não está dada pelo apego a uma ou outra teoria, mas deve-se à escuta das práticas educativas que, em seu tempo, desafiam a busca de novos referenciais. Continua o desafio do trânsito da consciência, do ser humano e da sociedade em direção ao "ser mais". A luta pela libertação dos oprimidos não perdeu a sua vigência. Mas ambos os processos são ressignificados em outro contexto sociopolítico (STRECK, 2009, p. 555).

$\mathrm{Na}$ perspectiva de Freire, constata-se que este cenário capitalista e colonial determina que a situação de opressão desumaniza, uma vez que os oprimidos não podem ser livres porque são negados em suas dimensões fundamentais e constitutivas. Torna-se evidente que em suas práticas políticas e pedagógicas, no método proposto pelo autor, os oprimidos vão buscar se libertar lutando contra quem os desumaniza. Mas a luta pela libertação deve ser a luta pela recuperação da humanidade. Segundo Freire: "a grande tarefa humanista e histórica dos oprimidos é a de libertar-se a si e aos opressores" (1983, p. 31). "A pedagogia do oprimido, nas trilhas da teoria da dependência, se fundamenta na visão da América Latina como lugar dependente, mas também de possibilidades" (STRECK, 2010, p. 330). A superação desta situação dependente será possível mediante uma dupla ruptura: externa, trazendo para a sociedade o centro das decisões; e interna, superando a sociedade cindida pelas classes. O alcance teórico e importância da obra de Paulo Freire podem ser vistos neste sentido:

Paulo Freire representa um momento de consolidação de um pensamento pedagógico latino-americano. Suas obras constituem o núcleo de um movimento educativo que na segunda metade do século XX passou a ser conhecido como Educação Popular (...). Trata-se de um momento de ruptura que é também um momento de libertação da pedagogia. Os teólogos haviam defendido a tese de que a teologia da libertação implica a libertação da teologia, no sentido de que ela vai muito além do ensino de conteúdos, mas se refere ao próprio processo de fazer teologia; para um grupo de filósofos, não poderia haver filosofia da libertação sem a libertação da filosofia. Em Freire temos um exercício de libertação da pedagogia. Em primeiro lugar, ela se torna uma pedagogia do outro, do oprimido (STRECK, 2010, p. 331).

Também os horizontes teóricos da Filosofia da Libertação de Enrique Dussel podem assim ser visualizados:

(C) ETD-Educação Temática Digital Campinas, SP v.19 $\quad$ n.1 $\quad$ p. 234-257 jan./mar. 2017 
a experiência inicial da Filosofia da Libertação consiste em descobrir o "fato" opressivo da dominação, em que sujeitos se constituem "senhores" de outros sujeitos, no plano mundial (desde o início da expansão europeia em 1492; fato constitutivo que deu origem à "Modernidade"), Centro-Periferia; no plano nacional (elites-massas, burguesia nacional-classe operária e povo); no plano erótico (homem-mulher); no plano pedagógico (cultura imperial, elitista, versus cultura periférica, popular, etc.); no plano religioso (o fetichismo em todos os níveis), etc. (DUSSEL, 1995, p. 18) (...). Por meio de sua Filosofia da Libertação analisa o processo opressivo da dominação, em que uns se tornam senhores de outros no plano mundial, questionando o discurso da modernidade. Tanto a sua filosofia quanto a sua Ética da Libertação possuem clara opção política pelas vítimas do sistema-mundo, compreendido como o processo de ampliação da influência cultural de um sistema inter-regional (alta cultura ou sistema civilizatório) a outras culturas. (OLIVEIRA; DIAS, 2012, p. 92).

O desafio para os oprimidos é de realizarem uma libertação que evite uma simples inversão dos polos da situação opressora. Logo, as tentativas de libertação que venham dos opressores jamais passarão de falsa generosidade, uma vez que, sua "suposta generosidade" implica na permanência da injustiça e na existência da pobreza diante à situação de necessidade. Entendemos que a verdadeira generosidade incide na luta pela restauração da plena humanidade na situação dos oprimidos e na superação destas "generosidades desiguais" (BOUFLEUER, 1991).

A concepção política de Freire é o que dá sentido à utopia de construção da nova sociedade livre, solidária e humanista. Tal projeto impele uma pedagogia da luta política a ser elaborada no processo da luta libertadora que os oprimidos tratam historicamente. Por essa razão que não deve existir receitas prontas e previsões de como acontecerá o processo político libertador, porém, existe a exigência radial do cultivo da dialogicidade para que possamos superar as práticas que reproduzem a opressão por uma nova cultura essencialmente humanizadora (ZITKOSKI, 2007).

Além de uma política pedagógica dos oprimidos, a união dos diferentes e daqueles que são postos de maneira desigual na sociedade, é exigida a luta contra os antagonismos de classe (FREIRE, 1995). Essa estratégia é fundamental na luta política de libertação no que se refere à supressão das classes, às relações de gênero, aos preconceitos étnicos e à desigualdade social reproduzida pela questão ambiental. Ou seja, o que está em jogo é a permanente luta de classes historicamente determinada:

(C) ETD-Educação Temática Digital Campinas, SP v.19 $\quad$ n.1 $\quad$ p. 234-257 jan./mar. 2017 
O que acontece é que luta é uma categoria histórica e social. Tem, portanto, historicidade. Muda de tempo-espaço. A luta não nega a possibilidade de acordos, de acertos entre as partes antagônicas (...). Há momentos históricos em que a sobrevivência do todo social, que interessa às classes sociais, lhes coloca a necessidade de se entenderem, o que não significa estarmos vivendo um novo tempo, vazio de classes e conflitos (FREIRE, 1994, p. 43).

Aqui se faz necessário, trazermos a contribuição dusseliana ao sentido e significado do termo libertação. Segundo Dussel (DUSSEL, 1986), a filosofia latino-americana terá sua originalidade ao se fundar sobre um projeto ético-antropológico interpretante do homem latino-americano. Tal projeto só poderá ser realizado se se constituir numa filosofia sobre novas bases metodológicas e históricas, sendo necessário ultrapassar os modelos metodológicos das filosofias européias que geram a alienação dos latino-americanos (OLIVEIRA, s/d). No plano metodológico, Dussel, partindo de Marx e da tradição semita, propõe uma nova formulação metodológica: o Método anadialético. Trata-se de uma metodologia filosófica original, porque se distingue e supera os procedimentos e categorias etnocêntricas da modernidade européia. O Método da Filosofia da Libertação terá seu ponto de partida no princípio da alteridade, na qual o pressuposto desse método estabelece que o discurso filosófico possui um caráter eminentemente ético, para além da dimensão puramente lógica. O discurso é válido ou inválido não pela sua correção lógica, mas pela razão de estar em acordo ou desacordo com a justiça (DUSSEL, 1986).

Para Dussel, a alienação consiste no fato de tomar o "outro enquanto instrumento" (objeto prático), isto é, enquanto um ser que serve de mediação para a realização das vontades do outro, aniquilando a semelhança e a distinção. Assim, a alienação resulta de uma práxis de dominação, que é a afirmação de um projeto totalizador opressor e autoritário. Nessa perspectiva, o projeto dominante impõe seu horizonte de abrangência, utilizando e instrumentalizando a tudo e a todos em função de uma cultura individualista, intrínseca ao capitalismo. Para assegurar a realização desse projeto dominador seus interessados promovem diversos tipos de alienação: do trabalho, da cultura, a política, a religiosa, a educativa (DUSSEL, 1977).

A libertação dentro deste horizonte consiste na desalienação das pessoas, povos, culturas e instauração de uma nova ordem fundada no respeito à alteridade e exterioridade humana, pois no processo de desalienação é preciso estar atento para não compreender o outro apenas como dimensão objetiva do mundo, como um meio para realizar determinado "projeto libertador". O ethos, o caráter da libertação exige não repetir a mesma ordem dominante e excludente, mas criar uma nova a serviço do outro. Esse ethos, para Dussel, se estrutura a partir do acolhimento alterativo, amor de justiça, acolhimento do outro

(C) ETD- Educação Temática Digital Campinas, SP $\quad$ v.19 $\quad$ n.1 $\quad$ p. 234-257 jan./mar. 2017 
enquanto outro que nos leva a compartilhar de sua miséria, da miséria de um povo, dos sofrimentos dos excluídos, dos explorados. A partir daí, somos provocados a buscar relações fraternas e solidárias que nos motiva à subversão do sistema para reconstruí-lo numa justiça real que afirma a dignidade humana.

Nesta perspectiva, o método de Dussel, tem como ponto de partida uma opção ética e uma práxis histórica concreta, aliando o rigor teórico e a ação ético-política à favor da libertação humana, uma vez que, a indiferença compactua com o sistema vigente. Ou seja, para Dussel é através da Ética da Libertação com seus princípios que traz em seu horizonte uma ética necessária em face da "miséria que aniquila a maioria da humanidade no final do século XX", junto com a destruição ecológica (DUSSEL, 2000, p. 15). Sua ética fundamenta-se também na criticidade que entendemos ser vital para a perspectiva ambiental assumida neste ensaio. Significa que sua razão crítica "permite o (auto) reconhecimento das vítimas do sistema-mundo (dominados: operários, índios, escravos, etc. e discriminados: mulheres, idosos, incapacitados, imigrantes, etc.), bem como o descobrimento de suas alteridades e autonomias, negadas pelo sistema-mundo vigente" (OLIVEIRA; DIAS, 2012, p. 98).

\section{CONSIDERAÇÕES FINAIS: EXCLUSÃO E LIBERTAÇÃO À LUZ DA CONTRIBUIÇÃO DUSSELIANA E FREIREANA}

Partindo das convergências e complementaridades nos dois autores, iremos tecer algumas contribuições sobre a exclusão e sua relação com a questão ambiental crítica. Para eles, em síntese, as bases éticas e antropológicas do projeto societário capitalista cimentam a negação da opressão como "naturalização das relações" (PERALTA; RUIZ, 2004). Trata-se de um modo de organização social que determina as formas de expropriação e dominação, sendo possível transformá-lo, mas com a condição de que cada sujeito e grupo social se transformem em sujeitos históricos conscientes de sua real condição de alienação no marco de uma sociedade desigual e constituída, portanto, em classes.

Temos a conviç̧ão que a abordagem ambiental crítica na América Latina não é um tema em voga (PORTO-GONÇALVES, 2012), mas atual e relevante, pois não podemos ignorar o contexto em que se dá a institucionalização dessa problemática no período que se abre desde os anos 1970, havendo uma contribuição específica na região a esse debate teóricopolítico. Nesse contexto, a grande contribuição latino americana está na crítica à sociedade capitalista (consumismo/produtivismo), alicerçada em categorias marxistas, acompanhada pela afirmação e pelo respeito aos povos originários e tradicionais, ao aprendizado com seus costumes, culturas e modos de produção, e à necessidade de diálogo de saberes. Desse

\section{(c) ETD-Educação Temática Digital Campinas, SP v.19 $\quad$ n.1 $\quad$ p. 234-257 jan./mar. 2017}


modo, a problemática ambiental ganha novos contornos quando analisada à luz dos protagonistas das lutas sociais que vêm transformando a ordem neoliberal latinoamericana. Mas é preciso não apenas constatar a existências dessas lutas sob um prisma não eurocêntrico (LEHER, 2007).

Para a vertente da questão ambiental assumida neste artigo, o desafio está na compreensão da dinâmica do processo de exclusão em consonância às lutas sociais e resistências dos trabalhadores, camponeses, povos originários que, ao defenderem seus territórios, produzem conhecimentos a partir de outras visões teóricas, epistêmicas e políticas, forjadas nas lutas contra as expropriações e em defesa do continente latinoamericano. $O$ que segundo Leher:

\begin{abstract}
Nesses espaços, a crítica ao padrão de acumulação, ao neodesenvolvimentismo e aos grandes eixos econômicos do IIRSA-Cosiplan localiza o chamado desenvolvimento sustentável e a economia verde no rol das ideologias e proposições econômicas dominantes, ainda que, frequentemente, sem utilizar os termos consagrados no léxico ambiental. (...). O foco, aqui são os conflitos ambientais provocados pelo padrão de acumulação do capital, pela nova geografia econômica mundial, que redefine os termos do desenvolvimento desigual e combinado do capitalismo $(2015$, p. 23).
\end{abstract}

Para Leher (2015), as bases para esse novo mapa social podem ser vistas nas diversas produções dos movimentos sociais, bem como nos estudos, documentos, manifestos, declarações de encontros que reúnem e renovam o pensamento crítico, revisitando uma agenda que parecia engavetada e fora de moda.

Entre os inúmeros documentos que asseguram esta perspectiva ambiental crítica, podemos citar o I Encontro sobre Cosmovisão e Identidade dos Povos Originários e Afrodescendentes, Cloc-Via Campesina, em 2011 que declara: condenados ao capitalismo (exploração dos recursos naturais e da força de trabalho), o Bem-viver é incompatível com o capitalismo. O II Encontro realizou a defesa dos saberes e da epistemologia dos povos articulada com o materialismo histórico, cuja formação política ideológica tem de ser realizada para fazer a leitura de classes. Assim, o documento aponta o arco de forças: “indígenas, camponeses, operários, estar nas lutas dos povos" (LEHER, 2015, p. 31).

Dentro deste quadro epistêmico-político traçado, tal perspectiva crítica das lutas ambientais e da dinâmica da exclusão encontra convergência com o movimento de justiça ambiental (LOUREIRO; LAYRARGUES, 2013). Na acepção de Leher (2015, p. 23):

(C) ETD- Educação Temática Digital Campinas, SP $\quad$ v.19 $\quad$ n.1 $\quad$ p. 234-257 jan./mar. 2017 


\section{DOI: $\underline{10.20396 / \text { etd.v19i1.8641259 }}$}

Importa exatamente a forma específica de articulação e subordinação das frações hegemônicas, a força do núcleo mais dinâmico do capital, impulsionado pelo setor financeiro e pelas megacorporações que determinam preços, quantidade e fluxos de mercadorias, calibrando, desse modo, a intensidade das expropriações e da exploração do trabalho.

Assim, podemos questionar: afinal qual seria a contribuição específica de Dussel e Freire? As propostas de ambos os pensadores para a questão ambiental auxiliam na adoção de estratégias políticas dirigidas à emancipação/libertação inscritas nos marcos de um processo de radicalização da questão social, sendo contrários à lógica neoliberal e desenvolvimentista hegemônicas, próprias da feição que o capitalismo assume na América Latina em sua matriz colonial.

A contribuição de Freire põe em evidência os fundamentos filosófico-políticos na sua teoria do conhecimento e ação no mundo que denominamos educação libertadora. Uma das principais concepções da educação libertadora é a educação se constituir em uma atividade em que os sujeitos, educadores e educandos, mediatizados pelo mundo educamse em comunhão (TOZONI-REIS, 2006). Esse processo, Freire chama de "conscientização", isto é, ao se aprofundarem no conhecimento da realidade vivida, real e concretamente pelos sujeitos, os quais têm as possibilidades de emergir no conhecimento de sua própria condição, ou seja, de sua própria vida.

A Pedagogia do Oprimido de Freire é um projeto coletivo que se assumido com liberdade e criatividade visa a um projeto de emancipação. Este processo histórico de transformação e libertação é desenvolvido no diálogo e no fazer conjunto com os sujeitos históricos, a multidão dos oprimidos, que constituem a "comunidade das vítimas" segundo Dussel (2000) e dos "oprimidos", segundo Freire. Vislumbra-se aí, um projeto pedagógico de libertação, uma práxis revolucionária em um projeto baseado na conscientização, que em Paulo Freire toma conotação eminentemente política, transformando-se numa relação que deve ser superada.

Apontamos que ambos pensadores tematizaram um pensamento filosófico-político que na história da América Latina e na história da educação tiveram expressiva influência nas pedagogias críticas e nos instrumentaliza para refletirmos criticamente a sociedade, bem como o contraponto à efetivação dos projetos societários vigentes que excluem o ser humano da possibilidade de vir-à-ser mais (ZITKOSKI, 2007).

Os pontos em comum sobre a temática da exclusão e libertação nos autores servem para tornar mais explícito o horizonte político que ambos trazem para o campo ambiental latino-americano. Os dois estão empenhados no tema da dominação e do seu contrário, a

(C) ETD-Educação Temática Digital Campinas, SP v.19 $\quad$ n.1 $\quad$ p. 234-257 jan./mar. 2017 
libertação, mostrando que esta requer a dialetização dos atos de conhecer e transformar a realidade. Para Dussel, as estruturas sociais interferem nas relações humanas que ocorrem no interior dos próprios países periféricos dependentes. Na América Latina, há projetos de dominação que são globais, entretanto, se realizam através de práticas específicas. Segundo o pensador argentino, quando o discurso libertador não está ligado à libertação dos níveis concretos de desigualdade e opressão, perde seu sentido (DAMKE, 1995).

Dussel e Freire propõem que é necessário, por um lado, integrar a pedagogia libertadora às lutas mais amplas pela libertação da sociedade como um todo, e por outro, ao colocar-se a serviço das transformações estruturais, não deve excluir dessa luta a formulação de projetos educativos que priorizem o conhecimento libertador. Para ambos, a pedagogia libertadora se presta "a serviço da libertação dos grupos ou dos povos oprimidos da América Latina e de outras nações ou continentes dominados pelo centro" (DAMKE, 1995, p. 142).

Compreendemos, à luz do pensamento freireano e dusseliano, que a questão ambiental e a educação são eminentemente políticas e implicam em construir pela participação radical dos sujeitos na vida social e pela permanente problematização da realidade, ações necessárias à transformação da sociedade. Trata-se de uma ontologia político-educativa que parte da certeza de que vivemos numa sociedade opressora e desigual com interesse de classe como reafirma Porto-Gonçalves $(2015$, p. 1):

\begin{abstract}
Todavia, uma coisa é o interesse particular de cada quem e o outro é o interesse do capital que, sendo uma relação social, implica muitas vezes antagonismos com outros grupos e classes sociais/povos/etnias/nacionalidades. Outras vezes, em determinadas conjunturas, interesses de classes proprietárias e não-proprietárias podem se aproximar mesmo contra o interesse geral da sociedade. É o que, com frequência, se vê com relação ao tema ambiental.
\end{abstract}

Em síntese, compreendemos que as posições de Dussel e Freire contribuem com o campo ambiental crítico na forma de repensarmos os fundamentos e a práxis ambiental compatíveis com o enfrentamento da desigualdade social da América Latina e o compromisso social manifestado no processo pedagógico crítico emancipatório. Para ambos os autores, a questão social pode ser repensada em contraposição à questão ambiental nos marcos do pensamento eurocêntrico. Tanto o pensador argentino, como o pedagogo brasileiro não deixaram dúvidas sobre o ponto de partida e sobre o ponto de chegada de suas reflexões: dos marginalizados, à exterioridade negada, à afirmação de sua positividade, ao conhecimento, à transformação, à libertação.

(C) ETD-Educação Temática Digital Campinas, SP v.19 $\quad$ n.1 $\quad$ p. 234-257 jan./mar. 2017 


\section{REFERÊNCIAS}

ANDREOLA, Balduino Antonio. Ética e solidariedade planetária. In: DALLA VECHIA, Agostinho Mario. (Org.). Ética: diversidade e diálogo na produção de referências para a educação. Pelotas: Seiva, 2003, p. 17-37.

ANDREOLA, Balduino Antonio. Freire e Habermas: aproximações possíveis e convergências impossíveis. s/d.

ASSMANN, Hugo; SUNG, Jung Mo. Competência e sensibilidade solidária. Petrópolis: Vozes, 2000.

BARROS, Albani de. Crise estrutural do capital e a destruição ambiental. Interfaces Científicas - Humanas e Sociais, Aracaju, SE, v. 01, n. 03, p. 21-31. jun. 2013. Disponível em: <https://goo.gl/3nCDQs $>$. Acesso em: 22 out. 2015. ISSN 2316-3801.

BOUFLEUER, José Pedro. Pedagogia latino-americana: Freire e Dussel. Ijuí: Unijuí, 1991.

CASTRO, Josué de. Subdesenvolvimento: causa primeira da poluição In: CASTRO, Josué de. Fome: um tema proibido. Rio de Janeiro: Civilização Brasileira, 2003.

COSTA, César Augusto Soares. Filosofia latino-americana: pressupostos para a "libertação ambiental". In: ENCONTRO DE PESQUISA EM EDUCAÇÃO AMBIENTAL, 6.; 2011, Ribeirão Preto, SP. Anais eletrônicos... Ribeirão Preto: UNESP, 2011. Disponível em: <http://goo.gl/kYsPtu>. Acesso em: 22 out. 2015.

COSTA, César Augusto Soares; LOUREIRO, Carlos Frederico Bernardo. Educação Ambiental crítica: contribuições à luz de Enrique Dussel e Paulo Freire. In: ENCONTRO DE PESQUISA EM EDUCAÇÃO AMBIENTAL; 7., 2013, Rio Claro, SP. Anais eletrônicos... Rio Claro: UNESP, 2013. Disponível em: <http://goo.gl/xODBln>. Acesso em: 22 out. 2015.

COSTA, César Augusto Soares; LOUREIRO, Carlos Frederico Bernardo. Interculturalidade, exclusão e libertação em Paulo Freire na leitura de Enrique Dussel: aproximações para a pesquisa em Educação Ambiental. Pesquisa em Educação Ambiental, Rio Claro, SP, v. 10, n. 01, p. 70-87. 2015. Disponível em: <http://goo.gl/DuQy88>. Acesso em: 22 out. 2015. ISSN 2177-580X.

DAMKE, Ilda Righi. O processo de conhecimento na pedagogia da libertação: as ideias de Freire, Fiori e Dussel. Petrópolis: Vozes, 1995.

DUSSEL, Enrique. 20 teses de política. Buenos Aires: CLACSO; São Paulo: Expressão Popular, 2007.

DUSSEL, Enrique. 1492: o encobrimento do Outro: a origem do mito da modernidade:

Conferências de Frankfurt. Petrópolis: Vozes, 1993.

(C) ETD-Educação Temática Digital Campinas, SP v.19 $\quad$ n.1 $\quad$ p. 234-257 jan./mar. 2017 
DUSSEL, Enrique. Ética da Libertação na idade da globalização e da exclusão. Petrópolis: Vozes, 2000.

DUSSEL, Enrique. Filosofia da Libertação. São Paulo: Loyola, 1977.

DUSSEL, Enrique. Filosofia da Libertação: crítica à ideologia da exclusão. São Paulo: Paulus, 1995.

DUSSEL, Enrique. Método para uma Filosofia da Libertação. São Paulo: Loyola, 1986.

FOSTER, Bellamy. A ecologia de Marx. Rio de Janeiro: Civilização Brasileira, 2005.

FOLADORI, Guillermo. Os limites do desenvolvimento sustentável. Campinas: Editora da Unicamp, 2001.

FERRARO, Alceu Ravanello. Neoliberalismo e políticas públicas: a propósito do propalado retorno às fontes. In: FERREIRA, Márcia Ondina Vieira; GUGLIANO, Alfredo Alejandro (Orgs.). Fragmentos da globalização na educação: uma perspectiva comparada. Porto Alegre: Artmed, 2000, p. 23-62.

FREIRE, Paulo. Ação cultural para a liberdade. 4 ed. São Paulo: Paz e Terra, 1979.

FREIRE, Paulo. À sombra desta mangueira. São Paulo: Olho d'água, 1995.

FREIRE, Paulo. Conscientização - teoria e prática da libertação: uma introdução ao pensamento de Paulo Freire. São Paulo: Centauro, 2001.

FREIRE, Paulo. Pedagogia da autonomia: saberes necessários à prática educativa. Rio de Janeiro: Paz \& Terra, 1996.

FREIRE, Paulo. Pedagogia da esperança. Rio de Janeiro: Paz e Terra, 1994.

FREIRE, Paulo. Pedagogia do oprimido. Rio de Janeiro: Paz e Terra, 1983.

FREIRE, Paulo; FAUNDEZ, Antonio. Por uma pedagogia da pergunta. Rio de Janeiro: Paz e Terra, 1995.

GENTILI, Pablo. (Org.). Pedagogia da exclusão: crítica ao neoliberalismo em educação. 2. ed. Petrópolis: Vozes, 1996.

GHIGGI, Gomercindo; OLIVEIRA, Avelino da Rosa. Formação humana e exclusão social: repensando possibilidades, revigorando limites. Educação UNISINOS, São Leopoldo, RS, v. 11, n. 01, p. 22-29. jan./abr. 2007. Disponível em: <http://goo.gl/IVJdZN>. Acesso em: 22 out. 2015. ISSN 2177-6210.

LAYRARGUES, Philippe Pomier. A dimensão freireana na Educação Ambiental. In: LOUREIRO, Carlos Frederico Bernardo; TORRES, Juliana Rezende (Orgs.). Educação Ambiental: dialogando com Paulo Freire. São Paulo: Cortez, 2014, p. 7-12.

(C) ETD-Educação Temática Digital Campinas, SP v.19 $\quad$ n.1 $\quad$ p. 234-257 jan./mar. 2017 
LEHER, Roberto. Iniciativa para a integração da infra-estrutura regional da América Latina, plano de aceleração do crescimento e a questão ambiental: desafios epistêmicos. In: LOUREIRO, Carlos Frederico Bernardo (Org.). A questão ambiental no pensamento crítico. Rio de Janeiro: Quartet, 2007, p. 223-255.

LOUREIRO, Carlos Frederico Bernardo; LAYRARGUES, Philippe Pomier. Ecologia política, justiça e Educação Ambiental crítica: perspectivas de aliança contra-hegemônica. Trabalho, Educação e Saúde, Rio de Janeiro, RJ, v. 11 n. 01, p.53-71. jan./abr.2013. Disponível em: <http://goo.gl/tYP159>. Acesso em: 22 out. 2015. ISSN 1981-7746.

LOUREIRO, Carlos Frederico Bernardo. Sustentabilidade e educação: um olhar da ecologia política. São Paulo Cortez, 2012.

LOUREIRO, Carlos Frederico Bernardo. Trajetória e fundamentos da Educação Ambiental. 3 ed. São Paulo: Cortez, 2009.

LUKÁCS, György. Ontologia do ser social: os princípios ontológicos fundamentais de Marx. São Paulo: Editora Ciências Humanas, 1979.

MARTINS, José de Souza. A sociedade vista do abismo: novos estudos sobre exclusão, pobreza e classes sociais. 2. ed. Petrópolis: Vozes, 2003.

MARTINS, José de Souza. Exclusão social e a nova desigualdade. São Paulo: Paulus, 1997.

MARX, Karl. O Capital. Crítica da Economia Política. [Livro I, Tomo II]. São Paulo: Abril Cultural, 1996.

MÉSZAROS, István. O desafio e o fardo do tempo histórico. São Paulo: Boitempo, 2007.

MÉSZAROS, István. A crise estrutural do capital. São Paulo: Boitempo, 2009.

OLIVEIRA, Avelino da Rosa. Exclusão social. In: STRECK; Danilo Romeu; REDIN, Euclides; ZITKOSKI, Jaime José. (Orgs.). Dicionário Paulo Freire. 2. ed. Belo Horizonte: Autêntica, 2010, p. 168-169.

OLIVEIRA, Avelino da Rosa. Marx e a exclusão. Pelotas: Seiva, 2004a.

OLIVEIRA, Avelino da Rosa. Sobre o alcance teórico do conceito "exclusão". Civitas - Revista de Ciências Sociais, Porto Alegre, RS, v. 04, n. 01, p. 159-188. jan./jun. 2004. Disponível em: <http://goo.gl/nizuKn>. Acesso em: 22 out. 2015. ISSN 1984-7289.

OLIVEIRA, Donato de. 0 método da Filosofia da Libertação, segundo Enrique Dussel. s/d.

OLIVEIRA, Ivanilde Apoliceno; DIAS, Alder Sousa. Ética da libertação de Enrique Dussel: caminho de superação do irracionalismo moderno e da exclusão social. Conjectura, Caxias do Sul, RS, v. 17, n. 03, p. 90-106. set./dez. 2012. Disponível em: <http://goo.gl/h4Gcdll>. Acesso em: 22 out. 2015. ISSN 2178-4612.

(C) ETD-Educação Temática Digital Campinas, SP v.19 $\quad$ n.1 $\quad$ p. 234-257 jan./mar. 2017 
PORTO-GONÇALVES, Carlos Walter. A ecologia política na América Latina: reapropriação social da natureza e reinvenção dos territórios. INTERthesis, Florianópolis, SC, v. 09, n. 01, p. 16-50. 2012. Disponível em: <https://goo.gl/QTylSJ>. Acesso em: 22 out. 2015. ISSN 18071384.

PORTO-GONÇALVES, Carlos Walter. De envolvimento, meio ambiente e interesse público. Rio de Janeiro, 2015.

PERALTA, Joaquín; RUIZ, Javier Reyes. Educação popular ambiental. Para uma pedagogia da apropriação do ambiente. In: LEFF, Enrique. (Coord.). A complexidade ambiental. São Paulo: Cortez, 2004, p. 241-280.

PINTO, Vicente Paulo dos Santos; ZACARIAS, Rachel. Crise ambiental: adaptar ou transformar? As diferentes concepções de educação ambiental diante deste dilema.

Educação em Foco, Juiz de Fora, MG, v.14, n. 02, p. 39-54. set. 2009/fev. 2010. Disponível em: <http://goo.gl/tmVZqN>. Acesso em: 22 out. 2015. ISSN 0104-3293.

RIBEIRO, Marlene. Exclusão: problematização do conceito. Educação e Pesquisa, São Paulo, SP, v. 25, n. 01, p. 35-49. jan./jun. 1999. Disponível em: <http://goo.gl/jqfp6T>. Acesso em: 22 out. 2015. ISSN 1678-4634.

STRECK, Danilo Romeu. Da Pedagogia do Oprimido às pedagogias da exclusão: um breve balanço crítico. Educação e Sociedade, Campinas, SP, v. 30, n. 107, p. 539-560. mai./ago. 2009. Disponível em: <http://goo.gl/uAjhWm>. Acesso em: 22 out. 2015. ISSN 1678-4626.

STRECK, Danilo Romeu. O Fórum Social Mundial e a agenda da educação popular. Revista Brasileira de Educação, Rio de Janeiro, RJ, n. 26, p. 58-69. mai./ago. 2004. Disponível em: < http://goo.gl/fzCEuG>. Acesso em: 22 out. 2015. ISSN 1809-449X.

STRECK, Danilo Romeu; ADAMS, Telmo; MORETTI, Cheron Zanini. Pensamento pedagógico em nossa América: uma introdução. In: STRECK, Danilo Romeu (Org.). Fontes da pedagogia latino-americana. Belo Horizonte: Autêntica, 2010, p. 19-35.

STRECK, Danilo Romeu; REDIN, Enrique; ZITKOSKI, Jaime José. Paulo Freire: uma cartografia intelectual. In: STRECK, Danilo Romeu; REDIN, Enrique; ZITKOSKI, Jaime José (Orgs.).

Dicionário Paulo Freire. 2. ed. Belo Horizonte: Autêntica, 2010, p. 15-22.

TOZONI-REIS, Marília Freitas de Campos. Educação ambiental: natureza, razão e história. Campinas: Autores Associados, 2004.

TOZONI-REIS, Marília Freitas de Campos. Temas ambientais como "temas geradores": contribuições para uma metodologia ambiental, crítica, transformadora e emancipatória. Educar em Revista, Curitiba, PR, n. 27, p. 93-110. jan./jun. 2006. Disponível em: <http://goo.gl/5pOU7Q>. Acesso em: 22 out. 2015. ISSN 1984-0411. VILLA, Fernando Gil. La exclusión social. Barcelona: Ariel, 2002.

(C) ETD-Educação Temática Digital Campinas, SP v.19 n.1 $\quad$ p. 234-257 jan./mar. 2017 
ZACARIAS, Raquel dos Santos. A lógica destrutiva do capital, crise ambiental, mudanças climáticas: os movimentos sociais e a educação ambiental. 2012. 178 f. Tese (Doutorado em Serviço Social) - Escola de Serviço Social, Universidade Federal do Rio de Janeiro, Rio de Janeiro, RJ, 2012.

ZITKOSKI, Jaime José. A Pedagogia freireana e suas bases filosóficas. In: GHIGGI, Gomercindo; SILVEIRA, Fabiane; PITANO, Sandro. (Orgs.). Leituras de Paulo Freire. Pelotas: Seiva, 2007, p. 229-248.

' Revisão gramatical do texto pela equipe da Revista ETD 